\title{
CARACTERIZAÇÃo DE LODO GERADO EM ESTAÇÕES DE TRATAMENTO DE ÁGUA: PERSPECTIVAS DE APLICAÇÃO AGRÍCOLA
}

\author{
Wander Gustavo Botero* \\ Universidade Federal de Alagoas, Campus Arapiraca, CP 61, 57309-005 Arapiraca - AL, Brasil \\ Ademir dos Santos, Luciana Camargo de Oliveira e Julio Cesar Rocha \\ Instituto de Química de Araraquara, Universidade Estadual Paulista, CP 355, 14801-907 Araraquara - SP, Brasil
}

Recebido em 11/7/08; aceito em 13/4/09; publicado na web em 17/9/09

\begin{abstract}
CHARACTERIZATION OF SLUDGE GENERATED IN WATER TREATMENT PLANTS: PROSPECTS FOR AGRICULTURAL APPLICATION. The work reported here involved the characterization of sludges produced at water treatment plants in JaboticabalSP using $\mathrm{FeCl}_{3}$ as flocculant, and in Taquaritinga-SP and Manaus-AM using $\mathrm{Al}_{2}\left(\mathrm{SO}_{4}\right)_{3}$ as flocculant. An evaluation was also made of the interaction of organic matter extracted from the sludges with different metal species. The results indicated that all the sludges produced at water treatment plants have an important agricultural potential and that their use depends on the characteristics of the raw water and the type of flocculant employed in conventional treatment. The humic substances extracted from the sludges showed different affinities for metal species, favoring eventual exchanges between potentially toxic metals and macro- and micronutrients. An alternative for the use of sludge in agriculture is to pretreat it to remove potentially toxic metals and enrich it with micro- and macronutrients that can be released to the plant.
\end{abstract}

Keywords: humic substances; WTP sludge; agricultural.

\section{INTRODUÇÃO}

A potabilização das águas naturais para fins de abastecimento público tem como principal função adequar a água bruta afluente à estação ao padrão de potabilidade vigente estabelecido pela Portaria 518 de 25 de Março de 2004. ${ }^{1}$ O tratamento de água consiste basicamente na remoção de partículas suspensas e coloidais, matéria orgânica, micro-organismos e outras substâncias possivelmente deletérias à saúde humana presentes nas águas. ${ }^{2}$

Existem no Brasil cerca de 7.500 estações de tratamento de água (ETAs) e aproximadamente $75 \%$ destas, utilizam processo denominado convencional para tratamento da água. Este consiste em operações de coagulação, floculação (as quais utilizam sulfato de alumínio e/ou cloreto férrico como floculantes), decantação e filtração para a clarificação da água, seguida de correção de $\mathrm{pH}$, desinfecção e, em alguns casos, de fluoretação. ${ }^{2,3}$

$\mathrm{Na}$ etapa de floculação e decantação é gerado um resíduo rico em matéria orgânica, micro e macro-nutrientes e metais potencialmente tóxicos, denominado lodo de estação de tratamento de água (LETA). ${ }^{4}$ Durante anos, o destino deste material vinha sendo os próprios mananciais de captação, agregando a estes uma elevada carga poluidora. ${ }^{3}$ A NBR 10.004/87 e a Lei Estadual de São Paulo 12.493/92 restringem e, até mesmo, proíbem essa prática, sugerindo que esses lodos devam ser reciclados e/ou reutilizados. Recentemente a fiscalização se tornou mais efetiva e as ETAs devem reutilizar esses lodos.

Diversas alternativas econômicas e tecnicamente viáveis, além de ambientalmente vantajosas para o destino final desse resíduo têm sido propostas, como disposição em aterros sanitários, uso na formação de biosólido, ${ }^{3}$ emprego na construção civil ${ }^{5-7}$ e aplicações industriais diversas. ${ }^{8-14}$ Uma das possibilidades de reutilização do LETA é seu emprego como aditivo em setores agrícolas. Por ser rico em matéria orgânica, micro e macro-nutrientes, sua utilização

*e-mail: wander_iq@yahoo.com.br pode diminuir os impactos ambientais associados à disposição inadequada desses resíduos. Além disto, é uma oportunidade para diminuir custos e aumentar a receita das empresas de saneamento.

A identificação de possíveis impactos ambientais devido à disposição final de LETAs originado pelas diferentes formas de tratamento da água pode ser feita pela determinação da sua composição química, filtrabilidade e resistência específica. Algumas espécies metálicas como cobre, zinco, níquel, chumbo, cádmio, crômio, manganês e, em especial, alumínio e ferro presentes no LETA, possuem ações tóxicas, podendo apresentar efeitos positivos ou negativos nas técnicas de tratamento, na disposição final e, até mesmo, na reutilização desses resíduos..$^{15}$

Assim, para a reutilização dos LETAs é de fundamental importância o estudo das características do lodo a ser reciclado e avaliar, por exemplo, a relação existente entre a matéria orgânica e espécies metálicas.

O principal objetivo desse trabalho foi caracterizar lodos in natura gerados em estações de tratamento de água que utilizam diferentes floculantes e águas de captação com características distintas, e avaliar a interação da matéria orgânica presente nesses lodos com algumas espécies metálicas.

\section{PARTE EXPERIMENTAL}

\section{Amostras de LETAs}

As amostras de LETAs foram coletadas nas estações de tratamento de água das cidades de Jaboticabal-SP (a qual utiliza cloreto férrico $\left(\mathrm{FeCl}_{3}\right.$ ) como floculante), Taquaritinga-SP e Manaus-AM (as quais utilizam sulfato de alumínio $\left(\mathrm{Al}_{2}\left(\mathrm{SO}_{4}\right)_{3}\right)$ como floculante). O LETA de Manaus é particularmente mais rico em matéria orgânica, pois é originado de água bruta captada no Rio Negro. Foram coletados aproximadamente $5 \mathrm{~L}$ de amostras no período de janeiro a março de 2006, por meio de amostragem simples, em dias de limpeza dos tanques de decantação, raspando-os com espátulas plásticas e acondicionadas em frascos de polietileno. 


\section{Preparo das amostras}

As amostras de LETAs foram transferidas para bandejas de madeira com medidas de 40 × $20 \mathrm{~cm}$, secas ao ar, desagregadas e peneiradas a $2 \mathrm{~mm}$.

\section{Análise para avaliação da fertilidade de LETAs}

A análise para avaliação da fertilidade de LETAs foi feita em triplicata determinando-se $\mathrm{K}^{+}, \mathrm{Ca}^{2+}, \mathrm{Mg}^{2+}$, $\mathrm{P}$, acidez potencial $(\mathrm{H}$ $+\mathrm{Al}$ ), capacidade de troca catiônica (CTC) e a saturação de bases, conforme procedimento descrito por Raij et al. ${ }^{16}$

\section{Determinação dos teores de matéria orgânica de LETAs}

O teor de matéria orgânica foi determinado por gravimetria, calcinando-se $10,0 \mathrm{~g}$ de amostra seca em mufla a $750{ }^{\circ} \mathrm{C}$ por $4 \mathrm{~h}$. A matéria inorgânica foi considerada como sendo o resíduo final de calcinação. ${ }^{17}$

\section{Análise elementar de LETAs}

Após tratamento preliminar (secagem, desagregação e peneiramento) nas amostras de LETAs, a análise elementar $(\mathrm{C}, \mathrm{H}, \mathrm{N}, \mathrm{O}$, S) foi feita em equipamento Thermo Finingan Flash EA1112 nas melhores condições sugeridas pelo fabricante.

\section{Digestão das amostras de LETAs e determinação de micro, macro-nutrientes e metais potencialmente tóxicos totais}

O processo de digestão das amostras foi feito segundo método da EPA previamente adaptado. ${ }^{18}$ Transferiram-se 2,00 g de amostra seca para frasco de forma alta de $500 \mathrm{~mL}$, adicionaram-se $10,0 \mathrm{~mL}$ de água desionizada e 10,0 mL de solução concentrada de ácido nítrico, aquecendo-se a mistura a $120^{\circ} \mathrm{C}$. As determinações de micro, macro-nutrientes e metais potencialmente tóxicos totais foram feitas por espectrometria de emissão atômica com plasma de argônio induzido (ICP-OES) ${ }^{18}$ nas melhores condições sugeridas pelo fabricante.

Extração e determinação de micro, macro-nutrientes e metais potencialmente tóxicos biodisponíveis em amostras de LETAs

Transferiram-se 2,50 g de amostra seca para frasco de $100 \mathrm{~mL}$ e adicionaram-se 50,0 mL de solução de ácido clorídrico $0,10 \mathrm{~mol}$ $\mathrm{L}^{-1}$. Agitou-se a suspensão por $2 \mathrm{~h}$ à temperatura ambiente em mesa agitadora de movimento circular horizontal com rotação de $200 \mathrm{rpm}$. Após repouso para decantação do material sólido, filtrou-se em papel Whatman 42, transferiu-se o filtrado para frasco de vidro e estocouse a $4{ }^{\circ} \mathrm{C} .{ }^{18}$ As determinações de micro, macro-nutrientes e metais potencialmente tóxicos foram feitas por espectrometria de emissão atômica com plasma de argônio induzido (ICP-OES), ${ }^{18}$ nas melhores condições sugeridas pelo fabricante.

\section{Extração de substâncias húmicas das amostras de LETAs}

As substâncias húmicas ( $\mathrm{SH}$ ) das amostras de LETAs foram extraídas segundo a metodologia recomendada pela IHSS. ${ }^{19,20}$ Transferiram-se 70,0 g de lodo para erlenmeyer, adicionou-se solução de $\mathrm{NaOH} 0,1 \mathrm{~mol} \mathrm{~L}^{-1}$ na razão $1: 10\left(\mathrm{~m} \mathrm{v}^{-1}\right)$ e deixou-se a mistura sob agitação mecânica em Jartest com rotação de $100 \mathrm{rpm}$ por $4 \mathrm{~h}$, sob atmosfera de nitrogênio. Centrifugou-se a mistura a 18000 x g por 30 min e separou-se o sobrenadante colocando-o para secar em estufa com renovação de ar.
Determinação da capacidade complexante das SH extraídas de amostras de LETAs por espécies metálicas

Para determinação da capacidade complexante das SH extraídas de amostras de LETAs por espécies metálicas ( $\mathrm{Ca}, \mathrm{Mg}, \mathrm{Cu}, \mathrm{Mn}, \mathrm{Al}$ e Fe) utilizou-se o sistema de ultrafiltração tangencial equipado com membrana de $1 \mathrm{kDa}$, como descrito por Santos et al. ${ }^{20}$ As titulações foram feitas em volume de $200 \mathrm{~mL}$ de solução de SH $100 \mathrm{mg} \mathrm{L}^{-1}$, ajustou-se o pH em 5,0 com solução de $\mathrm{NaOH} 0,1 \mathrm{~mol} \mathrm{~L}^{-1}$ e força iônica em 1,0 com solução de $\mathrm{NaNO}_{3} 0,1 \mathrm{~mol} \mathrm{~L}^{-1}$. Antes da adição das soluções padrão de espécies metálicas ( $\mathrm{Ca}, \mathrm{Mg}, \mathrm{Cu}, \mathrm{Mn}, \mathrm{Al} \mathrm{e} \mathrm{Fe}$ ), deixou-se o sistema bombeando por cerca de 5 min para condicionamento da membrana. A seguir, filtrou-se a primeira alíquota (cerca de $2 \mathrm{~mL}$ ), a qual corresponde ao tempo zero, ou seja, antes da adição da solução das espécies metálicas. Essa alíquota contém uma pequena quantidade de metal, correspondente à fração livre (não complexada às $\mathrm{SH}$ ), mais aquela fração ligada originalmente às $\mathrm{SH}$ com tamanho molecular menor que $1 \mathrm{kDa}$. Adicionaram-se alíquotas da solução de espécies metálicas à solução de $\mathrm{SH}$ para atingir concentrações finais de 0,$3 ; 0,6 ; 0,9 ; 1,65 ; 2,40 ; 3,15 ; 4,65 ; 6,15 ; 7,65 ; 9,15 \mathrm{mg} \mathrm{L}^{-1}$ em íons metálicos. Após cada adição deixou-se o sistema sob agitação por 10 min para atingir o equilíbrio de troca. ${ }^{20}$ Coletaram-se alíquotas (cerca de $2 \mathrm{~mL}$ ) e as concentrações das espécies metálicas livres foram determinadas por espectrometria de emissão atômica com plasma de argônio induzido (ICP-OES). ${ }^{18}$

\section{Influência do tempo na labilidade relativa entre ácido dietilenotriaminopenta-acético (DTPA) e espécies metálicas complexadas por SH extraídas de amostras de LETAs}

Para verificar a influência do tempo na labilidade relativa entre ácido dietilenotriaminopenta-acético (DTPA) e espécies metálicas complexadas por SH, utilizou-se sistema de ultrafiltração em fluxo tangencial equipado com membrana de $1 \mathrm{kDa}^{20} \mathrm{~A} 180,00 \mathrm{~mL}$ de solução de SH $100 \mathrm{mg} \mathrm{L}^{-1}$ adicionaram-se 10,00 mL de solução padrão multielementar (20 mg L ${ }^{-1}$ de $\mathrm{Ca}, \mathrm{Mg}, \mathrm{Cu}, \mathrm{Mn}, \mathrm{Al} \mathrm{e} \mathrm{Fe}$ ), ajustou-se o pH em 5,0 com solução de $\mathrm{NaOH} 0,10 \mathrm{~mol} \mathrm{~L}^{-1}$ e deixou-se sob agitação por $24 \mathrm{~h}$ a temperatura ambiente. Após bombeamento do sistema por cerca de 5 min filtrou-se a primeira alíquota (cerca de 2 $\mathrm{mL}$ ), a qual corresponde ao tempo zero, ou seja, antes da adição da solução de DTPA. Posteriormente, adicionaram-se 10,00 mL de solução de DTPA $1,5310^{-3} \mathrm{~mol} \mathrm{~L}^{-1}$, à solução de SH-Metais. Filtraram-se alíquotas em intervalos de 5, 10, 20, 30, 60, 120, 240, 360, 720 e $1440 \mathrm{~min}$, agitando-se o recipiente da amostra por cerca de $5 \mathrm{~min}$ antes de cada filtração. As determinações das espécies metálicas nas respectivas alíquotas foram feitas por espectrometria de emissão atômica com plasma de argônio induzido (ICP-OES). ${ }^{18}$

\section{RESULTADOS E DISCUSSÃO}

A análise para avaliação da fertilidade fornece informações referentes ao teor de matéria orgânica e da concentração de macro e micro-nutrientes disponíveis nos lodos, classificando-os quanto ao parâmetro fertilidade.

Uma das mais importantes características de qualquer resíduo a ser aplicado ao solo visando melhoria na fertilidade é a capacidade de troca de cátions (CTC), que representa a quantidade de íons positivos os quais podem ser retidos por atração eletrostática. Os principais cátions trocáveis presentes no solo são $\mathrm{H}^{+}, \mathrm{Ca}^{2+}, \mathrm{Mg}^{2+}, \mathrm{K}^{+}, \mathrm{Na}^{+} \mathrm{e} \mathrm{Al}^{3+}$ e os macro-nutrientes $\mathrm{P}, \mathrm{K}^{+}, \mathrm{Ca}^{2+}$ e $\mathrm{Mg}^{2+}$ são considerados essenciais para o desenvolvimento das plantas. ${ }^{16}$

A Tabela 1 lista os resultados de matéria orgânica, das análises para fins de fertilidade e razões atômicas $\mathrm{C} / \mathrm{N}$ nas amostras de LETAs de Jaboticabal-SP, Taquaritinga-SP e Manaus-AM. 
Tabela 1. Resultados de análises para fins de fertilidade e razões atômicas C/N feitas nas amostras de LETAs de Jaboticabal-SP, TaquaritingaSP e Manaus-AM

\begin{tabular}{|c|c|c|c|c|c|c|c|c|c|c|}
\hline $\begin{array}{l}\text { Amostras } \\
\text { de lodo }\end{array}$ & M.0.\% & $\begin{array}{c}\mathrm{K}^{+} \\
\mathrm{mmol} \\
\mathrm{dm}^{-3}\end{array}$ & $\begin{array}{c}\mathrm{Ca}^{2+} \\
\mathrm{mmol} \\
\mathrm{dm}^{-3}\end{array}$ & $\begin{array}{c}\mathrm{Mg}^{2+} \\
\mathrm{mmol} \\
\mathrm{dm}^{-3}\end{array}$ & $\begin{array}{c}\mathrm{P} \\
\mathrm{mg} \\
\mathrm{dm}^{-3}\end{array}$ & $\begin{array}{l}\mathrm{V} \\
\%\end{array}$ & $\begin{array}{c}\mathrm{H}+\mathrm{Al} \\
\mathrm{mmol} \\
\mathrm{dm}^{-3}\end{array}$ & $\begin{array}{l}\text { S.B. } \\
\text { mmol } \\
\mathrm{dm}^{-3}\end{array}$ & $\begin{array}{c}\mathrm{CTC} \\
\mathrm{mmol} \\
\mathrm{dm}^{-3}\end{array}$ & $\mathrm{C} / \mathrm{N}$ \\
\hline $\begin{array}{l}\text { ETA } \\
\text { Jaboticabal-SP }\end{array}$ & 20,5 & 2,1 & 147 & 23 & 6 & 82 & 38 & 172 & 210 & 8,40 \\
\hline $\begin{array}{l}\text { ETA } \\
\text { Taquaritinga-SP }\end{array}$ & 32,5 & 2,3 & 154 & 28 & 5 & 84 & 35 & 184 & 219 & 8,61 \\
\hline $\begin{array}{l}\text { ETA } \\
\text { Manaus-AM }\end{array}$ & 68,9 & 2,9 & 205 & 45 & 17 & 91 & 25 & 253 & 278 & 26,60 \\
\hline
\end{tabular}

O teor de matéria orgânica presente nos LETAs, listados na Tabela 1, refere-se à matéria orgânica total determinada por calcinação; os resultados mostraram que os lodos apresentam elevados teores de matéria orgânica, sendo maiores para LETAs de Manaus-AM, principalmente devido à elevada quantidade de matéria orgânica presente na água bruta captada proveniente do Rio Negro-AM.

De acordo com os resultados da análise de fertilidade dos LETAs comparados com dados de Raij et al. ${ }^{16}$ observa-se que os teores de cálcio, magnésio são considerados muito altos e potássio são considerados médios para as diferentes amostras. Os teores de potássio, cálcio e magnésio estão de acordo com aqueles encontrados por Oliveira et $_{\text {al. }}{ }^{7}$ e Canellas et al. ${ }^{21}$ para amostras de LETAs coletadas no Estado do Rio de Janeiro.

Pelo índice de saturação de bases, verifica-se que os lodos possuem elevada fertilidade (os índices de saturação de bases nas três amostras foram relativamente altos, cerca de $85 \%$ ), indicando que esse tipo de matriz possui grande potencial como aditivo agrícola. Teixeira et $_{\text {al. }}{ }^{4}$ avaliaram a disposição de LETA em solos degradados,

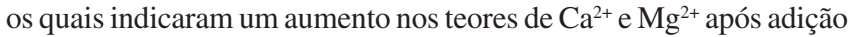
de LETA. Consequentemente, os solos apresentaram um aumento no $\mathrm{pH}$, devido a grande quantidade de $\mathrm{CaO}$ presente no lodo, o que pode interferir diretamente no processo de adsorção e solubilização de íons responsáveis pela concentração de nutrientes no solo.

De acordo com Minderman ${ }^{22}$ e Rosa et al. ${ }^{19}$ a decomposição dos constituintes orgânicos vegetais segue a seguinte ordem: açúcares, hemicelulose, celulose, lignina, graxas, fenóis. A razão $\mathrm{C} / \mathrm{N}$ é uma indicativa do grau de decomposição da matéria orgânica, isto é, quanto maior a razão $\mathrm{C} / \mathrm{N}$, há diminuição na quantidade de nitrogênio presente nas substâncias não húmicas indicando que houve degradação do material e, consequentemente, aumento na formação das substâncias húmicas. Os valores das razões C/N para os LETAs estão de acordo com os resultados dos teores de matéria orgânica, isto é, LETA de Jaboticabal-SP e Taquaritinga-SP apresentam razões $\mathrm{C} / \mathrm{N}$ menores que a de Manaus-AM, podendo-se inferir menor teor de SH nesses lodos.

O LETA de Manaus-AM apresentou maior teor de matéria orgânica e também grau de decomposição da matéria orgânica, comparado com o de Jaboticabal-SP e Taquaritinga-SP. Isto ocorre porque as águas que geram o lodo de Manaus-AM são originárias do Rio Negro, ricas em matéria orgânica, ${ }^{23,24}$ podendo-se inferir que as características das águas brutas influenciam nas características dos LETAs após o tratamento convencional.

A Figura 1 apresenta a distribuição dos teores de macro, micro-nutrientes e metais potencialmente tóxicos, totais e biodisponíveis presentes em amostras de LETAs de Jaboticabal-SP, Taquaritinga-SP e ManausAM. Os teores das espécies metálicas foram muito diferentes e por isso foi necessário expressar os resultados em log para melhor visualização.

Os resultados mostram que a presença e a biodisponibilidade de algumas espécies metálicas são distintas em relação à natureza do lodo. Quando se comparam os teores de ferro e alumínio nos lodos de Jaboticabal-SP, Taquaritinga-SP e Manaus-AM verificam-se que os
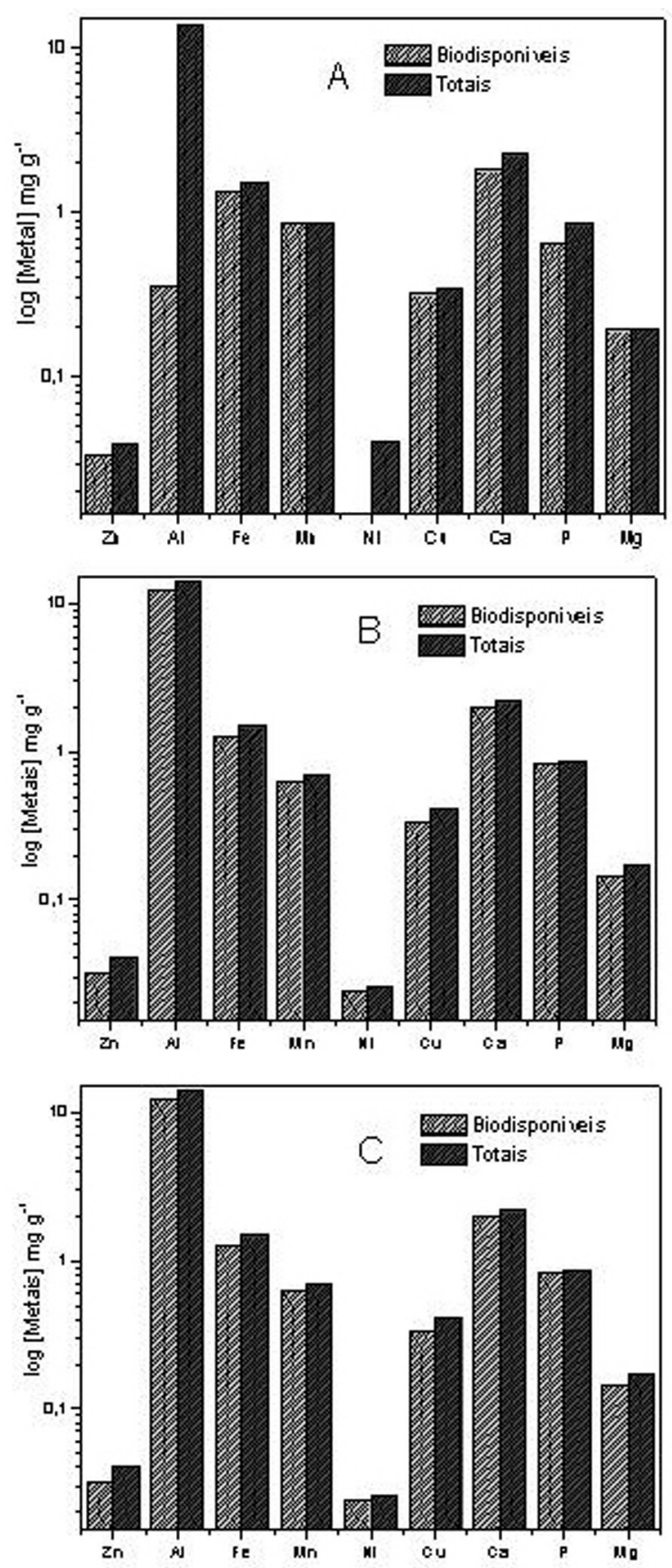

Figura 1. Distribuição de macro e micro-nutrientes e metais potencialmente tóxicos, totais e biodisponíveis determinados em amostras de LETAs de Jaboticabal-SP (A), Taquaritinga-SP (B) e Manaus-AM (C) 
mesmos apresentam teores equivalentes. Entretanto, teores de ferro e alumínio biodisponíveis apresentam diferenças significativas devido ao floculante utilizado nas ETAs, Ferro apresenta-se mais biodisponível no lodo de Jaboticabal (o qual utiliza cloreto férrico $\left(\mathrm{FeCl}_{3}\right)$ como floculante) e alumínio mais biodisponível nos lodos de Taquaritinga-SP e Manaus$\mathrm{AM}$ (os quais utilizam sulfato de alumínio, $\mathrm{Al}_{2}\left(\mathrm{SO}_{4}\right)_{3}$, como floculante).

Os elevados teores de ferro presentes no lodo de Manaus-AM podem também estar associados à presença desses metais nas águas do Rio Negro, devido à lixiviação de solos da Bacia Amazônica. ${ }^{23}$

Quando se comparam os demais metais (Zn, N, Mn, Ni, Cu, Ca, P e $\mathrm{Mg}$ ) presentes nos diferentes lodos, de maneira geral, observa-se que os teores são maiores nos LETAs de Jaboticabal-SP e Taquaritinga-SP, possivelmente devido ao aporte de efluentes domésticos e industriais das cidades do interior do Estado de São Paulo para os mananciais onde a água é captada.

\section{Estudos de complexação entre SH extraídas de LETAs e espécies metálicas}

Na determinação da capacidade complexante das SH extraídas de amostras de LETAs por espécies metálicas $(\mathrm{Ca}, \mathrm{Mg}, \mathrm{Cu}, \mathrm{Mn}, \mathrm{Al}$ e Fe), foi feita uma titulação com a espécie metálica de interesse e a solução de SH utilizando-se o sistema de ultrafiltração em fluxo tangencial equipado com membrana de $1 \mathrm{kDa} .{ }^{20}$

A Tabela 2 apresenta os valores determinados da capacidade complexante das substâncias húmicas extraídas de LETAs de Jaboticabal-SP, Taquaritinga-SP e Manaus-AM por espécies metálicas.

Tabela 2. Capacidade de complexação das substâncias húmicas extraídas de amostras de LETAs de Jaboticabal-SP, Taquaritinga-SP e Manaus-AM por espécies metálicas

\begin{tabular}{lcccccc}
\hline \multirow{2}{*}{$\begin{array}{l}\text { Amostras } \\
\text { de lodo }\end{array}$} & \multicolumn{6}{c}{ Capacidade complexante/ mmol metal $\mathrm{g}^{-1} \mathrm{SH}$} \\
& $\mathrm{Cu}$ & $\mathrm{Ca}$ & $\mathrm{Mg}$ & $\mathrm{Mn}$ & $\mathrm{Al}$ & $\mathrm{Fe}$ \\
\hline ETA Jaboticabal-SP & 0,32 & 0,27 & 0,50 & 0,37 & 0,26 & 0,24 \\
ETA Taquaritinga-SP & 0,30 & 0,25 & 0,54 & 0,19 & 0,23 & 0,34 \\
ETA Manaus-AM & 0,38 & 0,43 & 0,56 & 0,21 & 0,31 & 0,44 \\
\hline
\end{tabular}

As capacidades complexantes determinadas para as SH extraídas de LETAs fornecem informações quanto à afinidade das mesmas por diferentes espécies metálicas. De acordo com os dados da Tabela 2 , pode-se estabelecer a seguinte ordem crescente de afinidade dos íons metálicos pelas SH extraídas de amostras de lodos de ETAs de Jaboticabal-SP, Taquaritinga-SP e Manaus-AM:

LETA Jaboticabal-SP: $\mathrm{Fe}<\mathrm{Al}<\mathrm{Ca}<\mathrm{Cu}<\mathrm{Mn}<\mathrm{Mg}$; LETA Taquaritinga-SP: $\mathrm{Mn}<\mathrm{Al}<\mathrm{Ca}<\mathrm{Cu}<\mathrm{Fe}<\mathrm{Mg}$ e LETA Manaus-AM: $\mathrm{Mn}<\mathrm{Al}<\mathrm{Cu}<\mathrm{Ca}<\mathrm{Fe}<\mathrm{Mg}$.

Segundo Pearson, ${ }^{20,25}$ as espécies químicas podem ser classificadas como ácidos e bases "duros" e "moles" e os conceitos de "dureza e maciez" auxiliam a interpretar parte dos mecanismos envolvidos na complexação. A tendência dos ácidos "moles" ligarem-se às bases "moles" e dos ácidos "duros" ligarem-se às bases "duras" explica a forma que os elementos são encontrados na crosta terrestre. Segundo a classificação de Pearson existem duas classes principais: os elementos litofílicos e os calcofílicos. Os litofílicos são cátions duros, entre eles o magnésio, alumínio, lítio, cálcio, ferro, manganês, possuindo grande afinidade por bases duras, como $\mathrm{O}^{2-}$. Por outro lado, os calcofílicos são frequentemente encontrados em combinação com grupos aminos e cianos e incluem cobre, chumbo e cádmio.

Assim, comparando as capacidades complexantes das SH extraídas dos diferentes LETAs, observa-se que o magnésio (cátion duro) apresenta maior afinidade pelas substâncias húmicas. Isto pode estar relacionado com a grande quantidade de grupos oxigenados presentes nas SH extraídas de amostras de LETAs, favorecendo a complexação com magnésio. ${ }^{26}$

Ferro apresentou elevada afinidade para SH extraídas de LETA de Manaus-AM e Taquaritinga-SP e baixa afinidade para SH extraídas de LETA de Jaboticabal-SP. Esta diferença pode ser explicada devido à saturação das SH com íons ferro, considerando que o lodo de Jaboticabal-SP é originado de floculação via cloreto férrico.

Estudos propostos por Santos et al..$^{20}$ indicaram que para $\mathrm{SH}$ extraídas de amostras de turfa, o $\mathrm{Al}$ apresentou elevada afinidade frente a outros metais potencialmente tóxicos (por exemplo $\mathrm{Pb}, \mathrm{Cd}$ e $\mathrm{Cr}$ ). Entretanto, no presente trabalho o alumínio apresentou baixa afinidade, quando comparada com magnésio. Isto provavelmente se deve à diferença da razão carga/raio existente entre alumínio e magnésio. Como o magnésio apresenta razão carga/raio menor que o alumínio e ambos são cátions "moles", possivelmente o magnésio se complexa em sítios internos das $\mathrm{SH}$, onde para o alumínio há maior impedimento estérico.

Com base nas capacidades complexantes, pode-se inferir que os LETAs possuem relevante potencial agrícola, pois apresentam diferentes afinidades por espécies metálicas. Isto favorece eventuais trocas entre espécies metálicas, possibilitando fazer um pré-tratamento nos LETAs antes de sua aplicação na agricultura, para enriquecimento dos mesmos com macro e micro-nutrientes e retirar metais potencialmente tóxicos como, por exemplo, o Al.

Em ciência do solo, soluções de DTPA têm sido consideradas bons trocadores para a estimativa da biodisponibilidade de metais. ${ }^{16,27}$ A Figura 2 mostra a influência do tempo na labilidade relativa de espécies metálicas complexadas por substâncias húmicas extraídas de amostras de LETA de Jaboticabal-SP, Taquaritinga-SP e Manaus$\mathrm{AM}$, respectivamente.

Observa-se um comportamento cinético semelhante entre os metais estudados nas diferentes amostras. O equilíbrio de troca entre DTPA e metais complexados por substâncias húmicas só é atingido após cerca de $1 \mathrm{~h}$ de contato com as espécies metálicas. De maneira geral, as labilidades são menores para os LETAs de Manaus-AM, pois esses lodos são ricos em matéria orgânica decomposta apresentando, assim, uma maior interação com espécies metálicas.

Pode-se observar também, que o magnésio apresentou a menor labilidade relativa frente à DTPA para todas a amostras em estudo. Ou seja, o magnésio trocou menos com DTPA apresentando uma elevada afinidade com $\mathrm{SH}$ e estes dados corroboram com os resultados da capacidade de complexação, onde o magnésio apresentou maior afinidade pelas $\mathrm{SH}$ (Tabela 2).

O ferro é mais lábil nas amostras de LETAs de Jaboticabal-SP, a qual utiliza cloreto férrico como floculante, provavelmente devido ao LETA de Jaboticabal-SP estar saturado de íons ferro; consequentemente, tem menor capacidade de complexação e maior labilidade frente ao DTPA.

Para o manganês, os resultados obtidos corroboram com os encontrados por Rosa et al. ${ }^{27}$ e Santos et al.,${ }^{20}$ os quais estudaram a troca de metais originalmente complexados em amostras de turfas medicinais e solos, respectivamente, pelo quelante DTPA.

\section{CONCLUSÕES}

Os lodos estudados possuem elevados teores de matéria orgânica, sendo que o de Manaus-AM apresenta a matéria orgânica com maior teor de substâncias húmicas. Pela capacidade complexante, as SH extraídas de amostras de LETAS apresentaram diferentes afinidades pelas espécies metálicas devido a diferenças em suas características.

Os estudos da labilidade relativa entre DTPA e espécies metálicas complexadas pelas substâncias húmicas extraídas de amostras de LETAs 

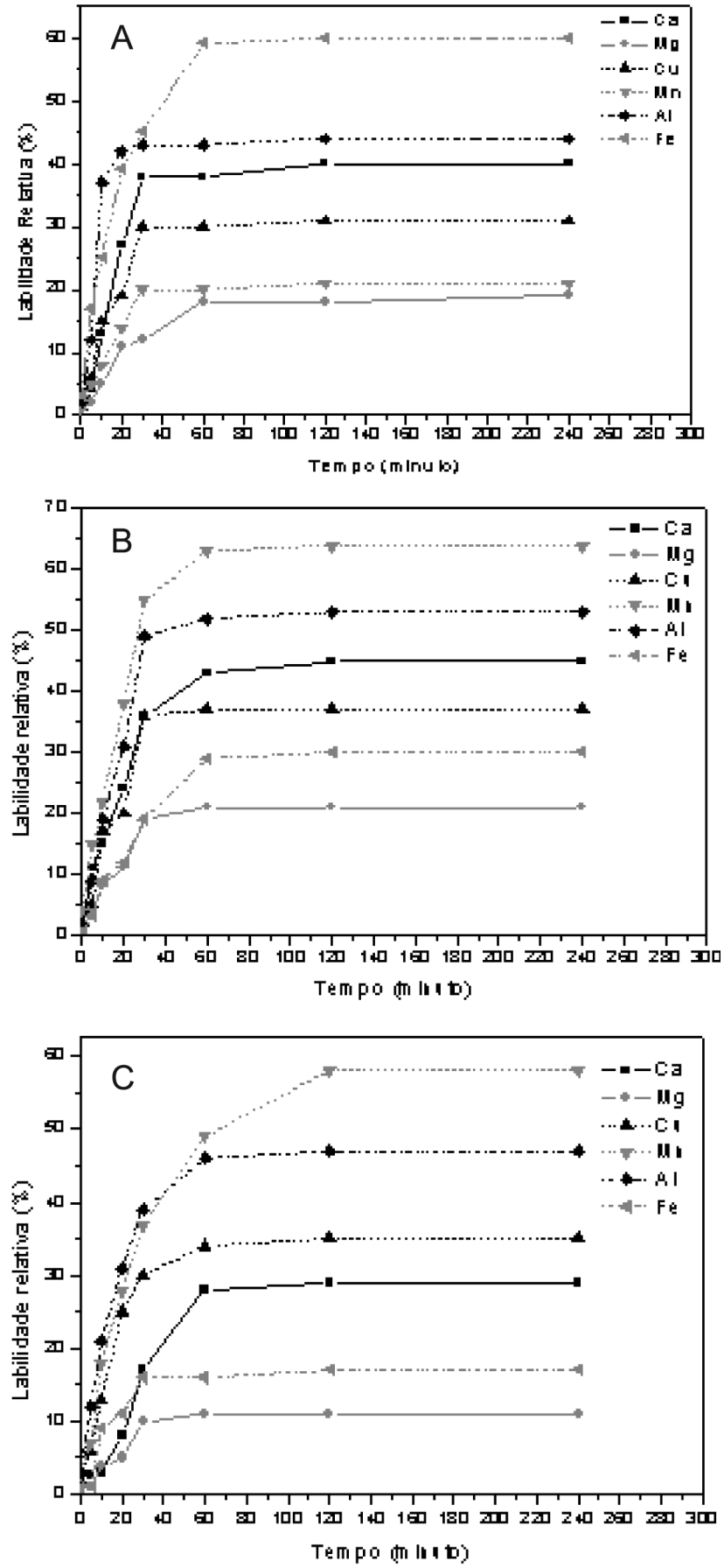

Figura 2. Influência do tempo de contato na labilidade relativa de espécies metálicas. Competição entre ácido dietiletilenotriaminopenta-acético (DTPA) e espécies SH-Metal, após complexação com substâncias húmicas extraídas de amostras de LETAs de Jaboticabal-SP (A), Taquaritinga-SP (B) e Manaus-AM(C)

mostraram que o equilíbrio de troca só é atingido após 1 h de contato. As labilidades relativas foram menores para os lodos de Manaus-AM, pois esses lodos são ricos em SH apresentando, assim, uma maior interação com espécies metálicas. O magnésio apresentou a menor labilidade relativa frente ao DTPA para todas as amostras em estudo, indicando uma elevada afinidade com as $\mathrm{SH}$, corroborando com os resultados da capa- cidade de complexação, onde o magnésio apresentou maior afinidade.

Os dados obtidos mostraram que os LETAs possuem relevante potencial agrícola e sua utilização é dependente das características da água bruta e do tipo de floculante utilizado no tratamento convencional. Uma alternativa para que os LETAs sejam utilizados na agricultura é um pré-tratamento, retirando espécies metálicas potencialmente tóxicas e enriquecendo-os com micro e macro-nutrientes que podem ser disponibilizados para as plantas.

\section{REFERÊNCIAS}

1. http://portal.saude.gov.br/portal/arquivos/pdf/portaria_518.pdf, acessada em Agosto 2009.

2. Cordeiro, J. S.; Campos, J. R. O.; Acta Gen. Méd. Gemellol. 1999, $50,52$.

3. Reis, E. L. T.; Cotrim, M. E. B.; Rodrigues, C.; Pires, M. A. F.; Beltrame Filho, O.; Rocha, S. M.; Cutolo, S. A.; Quim. Nova 2007, 30, 365.

4. Teixeira, S. T.; Melo, W. J.; Silva, E. T.; Pesq. Agropec. Bras. 2005, 40, 91.

5. Sales, A.; Cordeiro, J. S.; Resumos do Congresso Brasileiro de Engenharia Sanitária e Ambiental, Rio de Janeiro, Brasil, 1999.

6. Hoppen, C.; Dissertação de Mestrado, Universidade Federal do Paraná, Brasil, 2004

7. Oliveira, E. M. S.; Machado, S. Q.; Holanda, J. N. S.; Cerâmica 2004, 50,324 .

8. Reali, M. A. P.; Noções gerais de tratamento e disposição final de estações de tratamento de água, ABES: Rio de Janeiro, 1999.

9. Instituto Brasileiro de Geografia e Estatística; Atlas de Saneamento Pesquisa Nacional de Saneamento Básico 2000 (PNSB), IBGE: Brasília, 2004.

10. Cordeiro, J. S.; Tese de Doutorado, Universidade Federal de São Carlos, Brasil, 1993.

11. Lester, J. N.; Heavy Metals in Wasterwater and Sludge Treatment Process, CRCPress: Boca Raton, 1987.

12. Hoppen, C.; Portella, K. F.; Joukoski, A.; Trindade, E. M.; Andreoli, C. V.; Quim. Nova 2006, 29, 79.

13. Hoppen, C.; Portella, K. F.; Joukoski, A.; Cerâmica 2005, 51, 85.

14. Ferreira Filho, S. S.; Marchetto, M.; Engenharia Sanitária e Ambiental, ABES: Rio de Janeiro, 2006

15. Líbano, M.; Fundamentos de qualidade e tratamento de água, Átomo: Rio de Janeiro, 2005

16. Raij, B.; Andrade, J. C.; Cantarella, H.; Quaggio, J. A.; Análise química para avaliação da fertilidade de solos tropicais, IAC: Campinas, 2001.

17. Rosa, A. H.; Tese de Doutorado, Universidade Estadual Paulista, Brasil, 2001.

18. Santos, A.; Tese de Doutorado, Universidade de São Paulo, Brasil, 2003.

19. Rosa, A. H.; Rocha, J. C.; Furlan, M.; Quim. Nova 2000, 23, 472

20. Santos, A.; Botero, W. G.; Oliveira, L. C.; Bellin, I. C.; Rocha, J. C.; Mendonça, A. G. R.; J. Braz. Chem. Soc. 2007, 18, 824.

21. Canellas, L. P.; Santos, G. A.; Rumjanek, V. M.; Moraes, A. A.; Guridi, F.; Pesq. Agropec. Bras. 2001, 36, 1529.

22. Minderman, G.; J. Ecol. 1960, 56, 360.

23. Rosa, A. H.; Simões, M. L.; Oliveira, L. C.; Rocha, J. C.; Martin Neto, L.; Milori, D. M. B. P.; Geoderma 2005, 127, 1.

24. Serudo, R. L.; Oliveira, L. C.; Rosa, A. H.; Rocha, J. C.; Paterlini, W. C.; Silva, H. C.; Botero, W. G.; Geoderma 2007, 567, 152.

25. Pearson, R. G.; J. Am. Chem. Soc. 1963, 85, 3533.

26. Rocha, J. C.; Rosa, A. H.; Substâncias húmicas aquáticas: interações com espécies metálicas, UNESP: São Paulo, 2003.

27. Rosa, A. H.; Rocha, J. C.; Burba, P.; Talanta 2002, 58, 969. 